\title{
Sex differences in Alzheimer's disease risk: are we looking at the wrong hormones?
}

Two-thirds of individuals with Alzheimer's disease (AD) are women, owing largely to the fact that women outlive men (https://www.alz.org/ downloads/facts_figures_2012.pdf). Women's increased longevity, however, is not sufficient to explain the fact that women are 1.5 times more likely than men to develop the disease (Gao et al., 1998). After age 80, the incidence of $\mathrm{AD}$ is much higher in women than in men, such that the proportion of women with $\mathrm{AD}$ is almost twice the proportion of men with the disease (e.g., Zandi et al., 2002; Plassman et al., 2007). Moreover, once diagnosed with $\mathrm{AD}$, women decline more rapidly, both cognitively and functionally, compared to men (Ito et al., 2011; Tschanz et al., 2011).

To explain women's increased risk for $\mathrm{AD}$, and faster progression after onset, sex hormonesestrogens in particular-are often invoked. $\mathrm{Nu}-$ merous studies have established that age-related depletion of sex hormones increases the risk of $\mathrm{AD}$, prompting researchers to hypothesize protective roles of these hormones against $\mathrm{AD}$ (see Vest \& Pike, 2013, for a review). Further support for the sex-hormone hypothesis came from a series of studies on the relation between fertility and AD. Based on the hypothesis that pregnancy-induced changes in estrogen levels would increase AD risk, this line of work has revealed that women with a greater number of pregnancies have a higher risk of developing $\mathrm{AD}$ and/or a younger age of onset (Sobow and Kloszewska, 2004; Colucci et al., 2006). Even more persuasive is that having children increases the likelihood of developing $\mathrm{AD}$ in women but not in men (Colucci et al., 2006), and is positively correlated with $\mathrm{AD}$ neuropathology in women but not in men (Beeri, 2009). Furthermore, the association between parity and age of $\mathrm{AD}$ onset appears confined to women without the APOE4 allele, as it was not observed in women with the APOE4 allele in one study (Corbo et al., 2007), suggesting fertility is an independent risk factor for $\mathrm{AD}$ in women. Taken together, these findings provide perhaps the most compelling evidence for the sex hormone hypothesis of sex differences in risk for $\mathrm{AD}$.

The notion that brief periods of altered sex hormone levels lead to the development of $\mathrm{AD}$ pathology a half century later, however, is not altogether convincing for several reasons. First, the notion that pregnancy induces long-term decreases in basal estrogen has been suggested to explain the delayed temporal association between pregnancy and $\mathrm{AD}$. This explanation does not account for similar associations among parenthood, sex hormone levels, and risk of AD in men. Specifically, just as low estrogen levels increase the risk of $\mathrm{AD}$ in women, low testosterone is associated with an increased risk of $\mathrm{AD}$ in men. Moreover, men who become fathers evince a steeper decline in testosterone levels over time compared to men who remain childless (Gettler et al., 2011). Thus, if both motherhood and fatherhood are associated with decreased sex hormone levels, then fertility would be expected to increase the risk for $\mathrm{AD}$ in both sexes. But it does not. Second, the results of hormone replacement studies suggest strongly that hormone replacement increases $\mathrm{AD}$ risk, the opposite of what was predicted (e.g., Shumaker et al., 2003). Most importantly, the line of work based on the sex hormone hypothesis has not led to treatments for $\mathrm{AD}$, suggesting a need to consider alternative hypotheses linking female sex and $\mathrm{AD}$ risk. Findings from several lines of research implicate sex differences in the stress response as a promising candidate.

\section{The stress response}

In response to threat, a complex interaction among glands, hormones, and parts of the mid-brain ensues. In humans, stress triggers the release of corticotropin-releasing hormone $(\mathrm{CRH})$ from the para-ventricular nucleus of the hypothalamus. $\mathrm{CRH}$ stimulates the pituitary gland to release adrenocorticotrophic hormone (ACTH), which in turn causes the adrenal glands to release cortisol. The hypothalamic-pituitary-adrenal (HPA) axis is thus a key component of the stress response system, aberrations of which are associated with various stress-related illnesses.

Prolonged stress-induced release of glucocorticoids leads to alterations in the hippocampus (Sapolsky, 1996; Gould et al., 1998), including 
remodeling of dendrites (Gourley et al., 2013), reductions in long-term potentiation (Tadavarty et al., 2009; Kamal et al., 2014) or brain-derived neurotrophic factor (BDNF; Bath et al., 2013), increases in markers of oxidative stress (as reviewed by Rothman and Mattson, 2010), and reduced volume (Lupien et al., 1998). Stress also suppresses neurogenesis in the dentate gyrus (Gould et al., 1997, 1998), an effect that increases with advancing age (Simon et al., 2005). Additionally, stress alters dendritic morphology of prefrontal cortical neurons (Radley et al., 2004; Liston et al., 2006). The functional consequences of these changes include cognitive impairment, particularly in memory (see Lupien et al., 2005, for a review), and also in executive functioning (Plessow et al., 2012).

\section{Stress and AD}

In rodents, stress provokes misprocessing of the amyloid precursor protein, leading to increased levels of $\mathrm{A} \beta 40$ and $\mathrm{A} \beta 42$ in the hippocampi (Martisova et al., 2013), increases tau phosphorylation in the hippocampus and prefrontal cortex (Yang et al., 2014), and accelerates cognitive impairment (Cuadrado-Tejedor et al., 2012). Interestingly, these effects are observed in only "stress-sensitive" (rather than "stress-resistant") animals (Briones et al., 2012), suggesting that the apparent AD-inducing effects of stress are not inevitable, but require a particular vulnerability to the effects of stress.

In patients with $\mathrm{AD}$, both plasma and cerebrospinal fluid contain increased cortisol, the level of which is positively correlated with the degree of cognitive impairment (see, e.g., Dong and Csernansky, 2009), but unrelated to symptoms of depression (Hoogendijk et al., 2006). Longitudinal studies have found that experiencing major stressful life events is associated with younger age of onset in familial AD (Mejia et al., 2003). Furthermore, death of a spouse more than doubles the risk of $\mathrm{AD}$ in those who never remarry, a risk that is further increased in individuals who carry at least one APOE4 allele (Håkansson, 2009).

\section{Sex differences in the stress response}

\section{Cortisol}

Both preclinical and human studies show sex differences in the cortisol response to stress. In rodents, stress induces a greater cortisol response in males compared to females (Beck and Luine, 2002; Luine, 2002; Bowman et al., 2003). Findings in humans are less consistent, as they are more dependent on factors such as type of stressor, age of subjects, and the timing of hormone measures (see Kudielka and Kirschbaum, 2005, for a review).

In studies examining the effects of stress on cognition, the degree of cortisol response to stress, rather than the mere experience of it, better predicts the cognitive effects of stress (Wolf et al., 2001; Takahashi et al., 2004). Whereas findings in young adults do not consistently favor men or women, advancing age appears to place women at a disadvantage. In a meta-analysis of 45 studies, Otte and colleagues (2005) found that the effect of age on the cortisol response to a pharmacological or psychological stressor was almost three times higher in women than in men. Importantly, the effect sizes of studies that controlled for sex hormone variations in women (e.g., standardizing menstrual cycles, excluding women on oral contraceptives or hormone replacement therapy) did not differ from those that did not, suggesting that sex hormones do not alter the effect of aging on the stress response in women. In line with this finding, studies examining the effect of stress on cognition in older men and women find that an acute psychosocial stressor causes memory impairment in women only (Wolf et al., 1998; Almela et al., 2011).

\section{BDNF}

In addition to cortisol, the association between stress and BDNF is another mechanism by which women may be more vulnerable than men to $\mathrm{AD}$. In mice, stress reduces hippocampal BDNF in females but not in males (Yamaura et al., 2013). In rats exposed to stress, females show greater stress hormone (corticosterone) response, less cell proliferation in the dentate gyrus, and lower levels of hippocampal BDNF than males (Malheiros et al., 2014). In non-human primates, stress alters plasma BDNF in females but not males (Cirulli et al., 2009).

In humans, a cross-continent meta-analysis found that the Met66 polymorphism of the BDNF gene, shown to reduce the transport of BDNF, conferred an increased risk of $\mathrm{AD}$ in women but not in men (Fukumoto et al., 2010). While the role of estrogen in BDNF expression was postulated to underlie this finding, it is notable that BDNF is correlated with cortisol (Begluiomini et al., 2008). In a study of young adults, women with the Met66 (compared to the Val/Val) BDNF polymorphism had an increased cortisol response to a social stressor, whereas the same polymorphism was associated with a decreased cortisol response in men (Shalev et al., 2009). Taken together, these findings underscore the potential importance of 


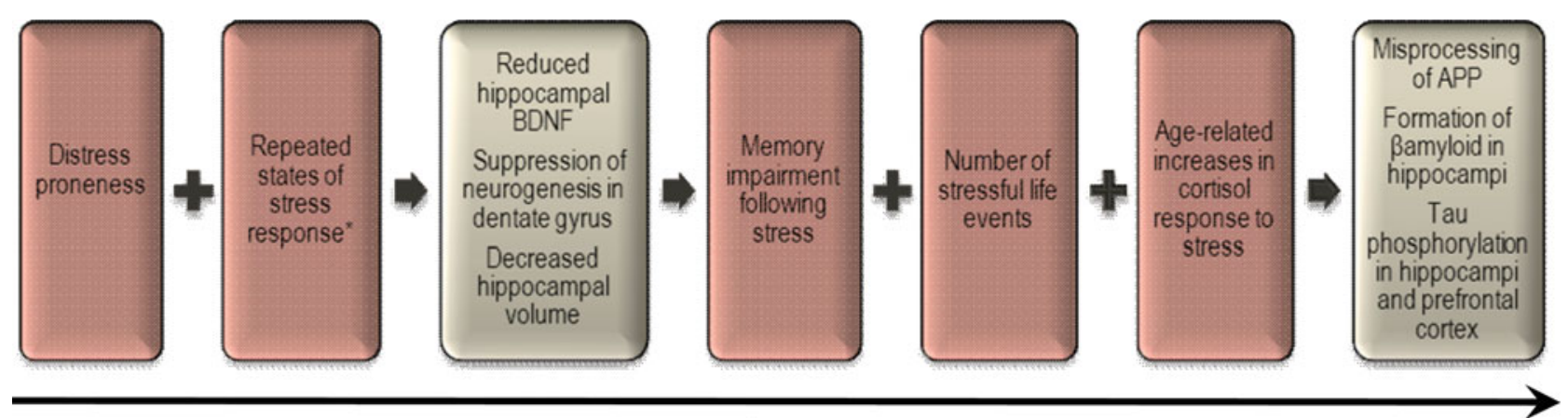

Age

Figure 1. Influence of stress on the development of AD. Factors for which women show greater vulnerability than men are shaded in red. * Increased vulnerability in women considers that pregnancy is a stressful event.

stress hormones in explaining women's increased risk of $\mathrm{AD}$.

\section{Sex differences in stress vulnerability}

In a 35-year longitudinal study of women, Johansson and colleagues (2010) found that reports of "frequent/chronic" stress during mid-life increased the risk of $\mathrm{AD}$ at follow-up. Similarly, a recent meta-analysis of five prospective studies (Terraccino et al., 2014) found that individuals in the top quartile of distress proneness (high scores on neuroticism) had a three-fold risk of AD. Sex differences in neuroticism are consistently found across the world, with women scoring higher than men (Lynn and Martin, 1997). The magnitude of the sex difference, slightly greater than one-half of a standard deviation, is almost identical in young and older adults (Costa et al., 2001; Chapman et al., 2007). These findings correspond to those from animal studies, and suggest that "stress-sensitive" individuals are at increased risk for $\mathrm{AD}$, and also that women are more vulnerable than men to this particular risk.

\section{Sex differences in major stressful life events}

Given the links between stress and risk of $\mathrm{AD}$, it is notable that one of life's most stressful eventsdeath of a spouse-is much more common in women than in men. Not only do women marry men who average two years their senior (Copen et al., 2012), they also live longer than men (81 vs. 76 years; Population Reference Bureau 2013 World Population Data Sheet). For these reasons, the sex difference in the proportion of individuals experiencing widowhood increases with age. From ages $75-84$, fewer than $20 \%$ of men, but over half of women $(54 \%)$ have lost a spouse to death. After age $85,35 \%$ of men and $72 \%$ of women have been widowed (U.S. Census Bureau, 2006). If stress can induce the development of $\mathrm{AD}$ pathology or hasten its clinical manifestation in both sexes, then women would be at greater risk for $\mathrm{AD}$ simply by virtue of being much more likely than men to experience death of a spouse, even if there were no sex differences in the stress response. In this sense, the higher incidence of $\mathrm{AD}$ in women after age 80 could, indeed, be explained by the fact that they outlive men.

\section{Pregnancy and stress hormones}

Considering the studies reviewed above, it is intriguing to consider whether findings from the fertility studies might lend themselves to reinterpretation in the context of stress, rather than sex, hormones. During pregnancy, the adrenal glands become hypertrophic, and basal cortisol levels rise. By the third trimester, cortisol increases to two to three times higher than in the nongestational period (Dörr et al., 1989), similar to the levels seen in Cushing's syndrome (Magiakou et al., 1997). At the same time, women's cortisol response to acute stress is attenuated (Kammerer et al., 2002). That repeated states of pregnancyinduced alterations in the stress response might lead to enduring perturbations of the HPA axis in a manner that increases the risk for $\mathrm{AD}$ is a tempting hypothesis. Indeed, multiparity reveals alterations in both diurnal cortisol and cortisol response to stress that are not evident in primiparous mothers (Tu et al., 2006a; 2006b).

\section{Conclusion}

Efforts to elucidate the mechanisms underlying sex differences in risk of $\mathrm{AD}$ have been dominated by research on sex hormones. While this work has done much to increase our knowledge of hormonal risk factors for $\mathrm{AD}$, it has not led to effective treatments. 
As depicted in the Figure, the preponderance of the evidence reviewed herein convincingly argues that stress hormones should be afforded their rightful place in the lineup of suspects underlying women's increased vulnerability to AD.

\section{Conflict of interest}

None

\section{CYNTHIA A. MUNRO}

Johns Hopkins School of Medicine Baltimore, MD, USA

Email: cmunro@jhmi.edu

\section{References}

Almela, M. et al. (2011). Salivary alpha-amylase response to acute psychosocial stress: the impact of age. Biological Psychology, 87, 421-429. doi: 10.1016/j.biopsycho.2011.05.008. https://www.alz.org/downloads/facts_figures_2012.pdf.

Bath, K. G., Schilit, A. and Lee, F. S. (2013). Stress effects on BDNF expression: effects of age, sex, and form of stress. Fournal of Neuroscience, 239, 149-156. doi: 10.1016/j.neuroscience.2013.01.074.

Beck, K. D. and Luine, V. N. (2002). Sex differences in behavioral and neurochemical profiles after chronic stress: role of housing conditions. Physiology and Behavior, 75, 661-673.

Beeri, M. S. (2009). Number of children is associated with neuropathology of Alzheimer's disease in women. Neurobiology of Aging, 30, 1184-1191.

Begliuomini, S. et al. (2008). Plasma brain-derived neurotrophic factor daily variations in men: correlation with cortisol circadian rhythm. Fournal of Endocrinology, 197, 429-435. doi: 10.1677/JOE-07-0376.

Bowman, R. E., Beck, K. D. and Luine, V. N. (2003). Chronic stress effects on memory. Sex differences in performance and monoamines. Hormones and Behavior, 43, $48-59$.

Briones, A. et al. (2012). Stress-induced anhedonia is associated with an increase in Alzheimer's disease-related markers. British fournal of Pharmacology, 165, 897-907. doi: 10.1111/j.1476-5381.2011.01602.x.

Chapman, B. P., Duberstein, P. R., Sörensen, S. and Lyness, J. M. (2007). Gender differences in five factor model personality traits in an elderly cohort. Personality and Individual Differences, 43, 1594-1603.

Cirulli, F. et al. (2009). Changes in plasma levels of BDNF and NGF reveal a gender-selective vulnerability to early adversity in rhesus macaques. Psychoneuroendocrinology, 34, 172-180. doi: 10.1016/j.psyneuen.2008.08.020.

Colucci, M. et al. (2006). The number of pregnancies is a risk factor for Alzheimer's disease. European fournal of Neurology, 13, 1374-1347.

Copen, C. E., Daniels, K., Vespa, J. and Mosher, W. D. (2012). First marriages in the United States: data from the
2006-2010 National Survey of Family Growth. National Health Statistics Reports; no 49. Hyattsville, MD: National Center for Health Statistics.

Corbo, R. M. et al. (2007). Combined effect of apolipoprotein e genotype and past fertility on age at onset of Alzheimer's disease in women. Dementia and Geriatric Cognitive Disorders, 24, 82-85.

Costa, P., Terracciano, A. and McCrae, R. R. (2001). Gender differences in personality traits across cultures: Robust and surprising findings. Fournal of Personality and Social Psychology, 81, 322-331.

Cuadrado-Tejedor, M., Ricobaraza, A., Frechilla, D., Franco, R., Pérez-Mediavilla, A. and Garcia-Osta, A. (2012). Chronic mild stress accelerates the onset and progression of the Alzheimer's disease phenotype in Tg2576 mice. Fournal of Alzheimer's Disease, 28:567-578. doi: 10.3233/JAD-2011-110572.

Dong, H. and Csernansky, J. G. (2009). Chronic mild stress accelerates the onset and progression of the Alzheimer's disease phenotype in Tg2576 mice. Effects of stress and stress hormones on amyloid- $\beta$ protein and plaque deposition. Fournal of Alzheimer's Disease, 18, 459-469. doi: 10.3233/JAD-2009-1152

Dörr, H. G. et al. (1989). Longitudinal study of progestins, mineralocorticoids, and glucocorticoids throughout human pregnancy. Fournal of Clinical Endocrinology \& Metabolism, 68, 863-868.

Fukumoto, N. et al. (2010). Sexually dimorphic effect of the Val66Met polymorphism of BDNF on susceptibility to Alzheimer's disease: new data and meta-analysis. American Fournal of Medical Genetics B, Neuropsychiatric Genetics, 153B:235-242. doi: 10.1002/ajmg.b.30986.

Gao, S., Hendrie, H. C., Hall, K. S. and Hui, S. (1998). The relationships between age, sex, and the incidence of dementia and Alzheimer disease: a meta-analysis. Archives of General Psychiatry, 55, 809-815.

Gettler, L. T., McDade, T. W., Feranil, A. B. and Kuzawa, C. W. (2011). Longitudinal evidence that fatherhood decreases testosterone in human males. Proceedings of the National Academy of Science, USA, 108, 16194-16199. doi: 10.1073/pnas.1105403108.

Gould, E., McEwen, B. S., Tanapat, P., Galea, L. A. M. and Fuchs, E. (1997). Neurogenesis in the dentate gyrus of the adult tree shrew is regulated by psychosocial stress and NMDA receptor activation. Fournal of Neuroscience, 17, 2492-2498.

Gould, E., Tanapat, P., McEwen, B. S., Flugge, G. and Fuchs, E. (1998) Proliferation of granule cell precursors in the dentate gyrus of adult monkeys is diminished by stress. Proceedings of the National Academy of Sciences, USA, 95, 3168-3171.

Gourley, S. L., Swanson, A. M. and Koleske, A. J. (2013). Corticosteroid-induced neural remodeling predicts behavioral vulnerability and resilience. Fournal of Neuroscience, 33, 3107-3112. doi: 10.1523/JNEUROSCI.2138-12.2013.

Håkansson, K. et al. (2009). Association between mid-life marital status and cognitive function in later life: population based cohort study. BMF, 339, b2462. doi: 10.1136/bmj.b2462.

Hoogendijk, W. J., Meynen, G., Endert, E., Hofman, M. A. and Swaab, D. F. (2006). Increased cerebrospinal 
fluid cortisol level in Alzheimer's disease is not related to depression. Neurobiology of Aging, 27, 780.e1-780.e2.

Ito, K. et al. (2011). Disease progression model for cognitive deterioration from Alzheimer's disease neuroimaging initiative database. Alzheimer's and Dementia, 7, 151-160. doi: 10.1016/j.jalz.2010.03.018.

Johansson, L. et al. (2010). Midlife psychological stress and risk of dementia: a 35-year longitudinal population study. Brain, 133, 2217-2224. doi: 10.1093/brain/awq116.

Kamal, A., Ramakers, G. M., Altinbilek, B. and Kas, M. J. (2014). Social isolation stress reduces hippocampal long-term potentiation: effect of animal strain and involvement of glucocorticoid receptors. Fournal of Neuroscience, 256, 262-270. doi: 10.1016/j.neuroscience.2013.10.016.

Kammerer, M., Adams, D., von Castelberg, B. and Glover, V. (2002). Pregnant women become insensitive to cold stress. BMC Pregnancy and Childbirth, 2, 8.

Kudielka, B. M. and Kirschbaum, C. (2005). Sex differences in HPA axis responses to stress: a review. Biological Psychology, 69, 113-132.

Liston, C. et al. (2006). Stress-induced alterations in prefrontal cortical dendritic morphology predict selective impairments in perceptual attentional set-shifting. Fournal of Neuroscience, 26, 7870-7874.

Luine, V. N. (2002). Sex differences in chronic stress effects on memory in rats. Stress, 5, 205-216.

Lupien, S. J. et al. (1998). Cortisol levels during human aging predict hippocampal atrophy and memory deficits. Nature Neuroscience, 1, 69-73.

Lupien, S. J. et al. (2005). Stress hormones and human memory function across the lifespan. Psychoneuroendocrinology, 30, 225-242.

Lynn, R. and Martin, T. (1997). Gender differences in extraversion, neuroticism, and psychoticism in 37 nations. The fournal of Social Psychology, 137, 369-373.

Magiakou, M. A., Mastorakos, G., Webster, E. and Chrousos, G. P. (1997). The hypothalamic-pituitaryadrenal axis and the female reproductive system. Annals of the New York Academy of Sciences, 816, 42-56.

Malheiros, J. M. et al. (2014). Repetitive noxious neonatal stimuli increases dentate gyrus cell proliferation and hippocampal brain-derived neurotrophic factor levels. Hippocampus, 24, 415-423. doi: 10.1002/hipo. 22235.

Martisova, E., Aisa, B., Guereñu, G. and Ramírez, M. J. (2013). Effects of early maternal separation on biobehavioral and neuropathological markers of Alzheimer's disease in adult male rats. Current Alzheimer Research, 10, 420-432.

Mejía, S., Giraldo, M., Pineda, D., Ardila, A. and Lopera, F. (2003). Nongenetic factors as modifiers of the age of onset of familial Alzheimer's disease. International Psychogeriatrics, 15, 337-349.

Otte, C., Hart, S., Neylan, T. C., Marmar, C. R., Yaffe, K. and Mohr, D. C. (2005). A meta-analysis of cortisol response to challenge in human aging: importance of gender. Psychoneuroendocrinology, 30, 80-91.

Plassman, B. L. et al. (2007). Prevalence of dementia in the United States: the aging, demographics, and memory study. Neuroepidemiology, 29, 125-132.
Plessow, F., Kiesel, A. and Kirschbaum, C. (2012). The stressed prefrontal cortex and goal-directed behaviour: acute psychosocial stress impairs the flexible implementation of task goals. Experimental Brain Research, 216, 397-408. doi: 10.1007/s00221-011-2943-1.

Population Reference Bureau 2013 World Population Data Sheet, www.prb.org.

Radley, J. J. et al. (2004). Chronic behavioral stress induces apical dendritic reorganization in pyramidal neurons of the medial prefrontal cortex. Neuroscience, 125, 1-6.

Rothman, S. M. and Mattson, M. P. (2010). Adverse stress, hippocampal networks, and Alzheimer's disease. Neuromolecular Medicine, 12, 56-70. doi: 10.1007/s12017-009-8107-9.

Sapolsky, R. M. (1996). Stress, glucocorticoids, and damage to the nervous system: the current state of confusion. Stress, 1, 1-19.

Shalev, I. et al. (2009). BDNF Val66Met polymorphism is associated with HPA axis reactivity to psychological stress characterized by genotype and gender interactions. Psychoneuroendocrinology, 34, 382-388. doi: 10.1016/j.psyneuen.2008.09.017.

Shumaker, S. A. et al. (2003). Estrogen plus progestin and the incidence of dementia and mild cognitive impairment in postmenopausal women. The Women's Health Initiative Memory Study: A randomized controlled trial. $\mathcal{F A M A}, 289$, 2651-2662.

Simon, M., Czéh, B. and Fuchs, E. (2005). Age-dependent susceptibility of adult hippocampal cell proliferation to chronic psychosocial stress. Brain Research, 1049, 244 248.

Sobow, T. and Kloszewska, I. (2004). Parity, number of pregnancies, and the age of onset of Alzheimer's disease. fournal of Neuropsychiatry and Clinical Neurosciences, 16, 120-121.

Tadavarty, R., Kaan, T. K. and Sastry, B. R. (2009). Long-term depression of excitatory synaptic transmission in rat hippocampal CA1 neurons following sleep-deprivation. Experimental Neurology, 216, 239-242. doi: 10.1016/j.expneurol.2008.11.012.

Takahashi, T. et al. (2004). Social stress-induced cortisol elevation acutely impairs social memory in humans. Neuroscience Letters, 363:125-130.

Terracciano, A. et al. (2014). Personality and risk of Alzheimer's disease: new data and meta-analysis. Alzheimer's and Dementia, 10, 179-186. doi: 10.1016/j.jalz.2013.03.002.

Tschanz, J. T. et al. (2011). Progression of cognitive, functional, and neuropsychiatric symptom domains in a population cohort with Alzheimer dementia: the cache county dementia progression study. American fournal of Geriatric Psychiatry, 19, 532-542. doi: 10.1097/JGP.0b013e3181faec23.

Tu, M. T., Lupien, S. J. and Walker, C. D. (2006a). Multiparity reveals the blunting effect of breastfeeding on physiological reactivity to psychological stress. Fournal of Neuroendocrinology, 18, 494-503.

Tu, M. T., Lupien, S. J. and Walker, C. D. (2006b). Diurnal salivary cortisol levels in postpartum mothers as a function of infant feeding choice and parity. Psychoneuroendocrinology, 31, 812-824. 
Vest, R. S. and Pike, C. J. (2013). Gender, sex steroid hormones, and Alzheimer's disease. Hormones and Behavior, 63, 301-307. doi: 10.1016/j.yhbeh.2012.04. 006.

Weinstein, G. et al. (2014). Serum brain-derived neurotrophic factor and the risk for dementia: the Framingham Heart Study. $\mathcal{F} A M A$ Neurology, 71, 55-61. doi: $10.1001 /$ jamaneurol.2013.4781.

Wolf, O. T., Kudielka, B. M., Hellhammer, D. H., Hellhammer, J. and Kirschbaum, C. (1998). Opposing effects of DHEA replacement in elderly subjects on declarative memory and attention after exposure to a laboratory stressor. Psychoneuroendocrinology, 23, 617629.

Wolf, O. T., Schommer, N. C., Hellhammer, D. H., McEwen, B. S. and Kirschbaum, C. (2001). The relationship between stress-induced cortisol levels and memory differs between men and women.

Psychoneuroendocrinology, 26, 711-720.

Yamaura, K., Ishiwatari, Y. B. M., Oishi, N., Fukata, H. and Ueno, K. (2013). Sex differences in stress reactivity of hippocampal BDNF in mice are associated with the female preponderance of decreased locomotor activity in response to restraint stress. Zoological Science, 30, 1019-1024. doi: 10.2108/zsj.30.1019.

Yang, C. et al. (2014). Changes in tau phosphorylation levels in the hippocampus and frontal cortex following chronic stress. Brazilian fournal of Medical and Biological Research, 47, 237-244. doi: 10.1590/1414-431X20133275.

Zandi, P. P. et al. (2002). Hormone replacement therapy and incidence of Alzheimer disease in older women: the Cache County Study. $\mathcal{F A M A}, 288,2123-2139$. 